INTERNATIONAL JOURNAL OF RESEARCHES IN BIOSCIENCES, AGRICULTURE AND TECHNOLOGY

(C) VISHWASHANTI MULTIPURPOSE SOCIETY (Global Peace Multipurpose Society) R. No. MH-659/13(N) www.vmsindia.org

\title{
ALGAE BIOMASS PRODUCTION AS A TOOL FOR GLOBAL WARMING MITIGATION
}

\author{
S. P. Shukla ${ }^{1}$ and W. A. A. D. Lanka Wickramasinghe ${ }^{1,2}$ \\ ${ }^{1}$ Aquatic Environment and Health Management Division, \\ Central Institute of Fisheries Education, Versova, Mumbai, India. \\ ${ }^{2}$ Fisheries and Marine Science Division, Ocean University, Tangalle, Sri Lanka. \\ spshukla@cife.edu.in
}

\begin{abstract}
:
An ever increasing demand for energy, particularly in developing countries has resulted in an unprecedented increase in atmospheric carbon dioxide concentration. Microalgae are a unicellular or multicellular, photosynthetic group of microorganisms which are able to fix $\mathrm{CO} 2$ efficiently from different sources, such as industrial exhaust gases, soluble carbonate salts and the atmosphere. The predictions indicate that there will be several folds increase in $\mathrm{CO}_{2}$ concentration by the end of century resulting in further warming of the planet. To reduce the carbon dioxide concentration requires dedicated efforts while meeting the energy demand. Combination abilities of $\mathrm{CO} 2$ fixation, biofuel production, and wastewater treatment by microalgae may provide a very promising alternative to current $\mathrm{CO} 2$ mitigation strategies.
\end{abstract}

Keywords: Algal production, High Rate Ponds (HRP's), Global warming, $\mathrm{CO}_{2}$ Biosequestration, Wastewater treatment

\section{Introduction:}

Global warming is a manifestation of increased concentration of atmospheric carbon dioxide (Kareiva et al., 1993). Therefore, sequestration of atmospheric $\mathrm{CO}_{2}$ is a major requisite for global warming mitigation. Consumption of fossil fuels during past decade has resulted in a considerable increase in carbon dioxide concentration in the environment. The increased concentration has crossed the threshold of capacity of various processes including photosynthesis for atmospheric carbon sequestration, resulting into global warming phenomenon. The anthropogenic activities such as deforestation, marine pollution, industrial and vehicular emissions have further aggravated the problem.

The mitigation of global warming requires a two pronged approach which involves deep cut on emissions and a simultaneous increase in atmospheric carbon sequestration through innovative technologies and policy formulations (Victor et al., 2014). Microalgae present one of the few technologies for the capture and utilization of atmospheric carbon dioxide through the process of photosynthesis. The biomass produced contributes in reducing the carbon dioxide concentration in the atmosphere, and also provides a feedstock for biofuel production (IPCC, 1996; Sawayama et al., 1999).

An upscaling of the biomass production of algae in large open ponds is a lucrative option for atmospheric carbon sequestration. Further, industrial emissions such as flue gases (mixture of oxides of carbon, nitrogen and sulphur) can be utilized for algal growth hence, reducing the cost of biomass production. The harvested biomass of algae when converted to biofuels such as biodiesel contributes to replacement of fossil fuels in a phased manner. Global warming mitigation through algal biomass production poses no risk to conventional agriculture since algae are ubiquitous organisms and can be grown in wastewater, inland saline water and seawater (Sandeep et al., 2013; 2015). Further, wasteland, saline and sodic soils can be effectively utilized for algal pond construction without impacting the agricultural lands. In view of no conflict with conventional agriculture, there is ample scope for upscaling of algal biomass production.

Photosynthesis is the process where atmospheric carbon dioxide is fixed in the form of carbohydrates through an enzymatic pathway. Among plants, aquatic microalgae are effective in the fixation of atmospheric carbon dioxide because their carbon fixation rates are higher than those of terrestrial plants. Hence, microalgal cultivation provides a viable option for capture and sequestration of atmospheric carbon dioxide.

The advantages of microalgae based carbon sequestration systems are;

- Algal culture does not require high purity $\mathrm{CO}_{2}$ gas. Flue gas containing a mixture of $\mathrm{CO}_{2}$ and $\mathrm{NO}_{2}$ can be fed directly to the algal ponds.

- The combustion products in flue gas such as $\mathrm{NO}_{\mathrm{x}}$ and $\mathrm{SO}_{\mathrm{x}}$ can be utilized as nutrients for microalgal culture. This could reduce the cost of production of algae.

- Microalgae are source of many high value compounds viz. Phycocyanin, Carotenoids, Gamma linolenic acid etc. Sale of these products can offset the input cost. 
- Microalgal systems have minimal negative impacts on environment, and are more eco-friendly as compared to chemical and physical sequestration.

Wastewater treatment through microalgae:

Disposal and treatment of wastewater generated in habitation are one of the key environmental challenges faced in urban localities due to an escalating population of the recent decade. Nutrient overloaded wastewater generated in municipalities has been either untreated or partially treated and directly fed into the nearby water bodies regularly, resulting in nutrient enrichment and algal blooms. Traditional wastewater treatment options are energy and capital intensive as well as ineffective in their capacity of removing nutrients entirely.

Therefore, algal processes are valuable in terms of removing nutrients through carbon sequestration and a resultant biomass production (Woertz et al., 2009). Algae grows rapidly and assimilate nutrients ( $\mathrm{C}, \mathrm{N}$ and $\mathrm{P}$ ) available in wastewater (Mahapatra et al., $2013 a$, b) hence they are useful in nutrient remediation. This algal biomass provides aeration in the water body in addition to having a good valorization potential with biofuel prospects (Mahapatra et al., 2013a, b)

\section{Biofuel from microalgae}

The ability to accumulate lipids and higher growth rates of algae have made them a viable substrate for biofuel when compared to other biofuel feed-stocks (Damiani et al., 2010; Chanakya et al.,2012; Ramachandra et al., 2013). Microalgae rich in lipids and hydrocarbons are being exploited now in order to mitigate the impending fuel oil crisis (Ramachandra et al., 2009) as they are renewable, carbon neutral and viable substitutes for fossil fuels. Algae based biofuel generation coupled with wastewater treatment would also counter the reduction of environmental externalities and extra energy operating cost (Chen et al., 2011)

\section{Algal cultivation systems}

1. High Rate Ponds (HRP's): HRP's are race way type ponds with a depth of $0.2-1 \mathrm{~m}$. The culture in the pond is mixed by a paddle wheel. The horizontal water velocity is approximately $0.15-0.3 \mathrm{~m} / \mathrm{s}$. The configuration of an HRP may vary depending upon the number of loops (single or multiple) around a central dividing wall. The pond bottom may be either lined or unlined depending upon soil conditions. $\mathrm{CO}_{2}$ is added into a counter current gas sparging sump $\quad(\sim 1.5 \mathrm{~m}$ depth) creating a turbulent flow in the raceway pond.

Continuously Stirred Tank Reactor (CSTR): CSTR are used for continuous culture of microalgae. It runs at a steady state with continuous flow of culture medium in the culture vessel, and a simultaneous withdrawal of algal suspension from the unit for harvesting and further applications. The culture is continuously stirred through a motor based stirrer.

CSTR has following advantages:

- Continuous operation is possible, Good temperature control, Simplicity of construction, Low operating cost and Easy to clean etc..

There are few disadvantages also such as:

- Lowest conversion per unit volume, Loss of yield due to settling of algal cells at the bottom or walls if agitation is not adequate etc..

(From online information about US patent no.US 20120202242 A1)

Carbon sequestration by algae varies in a species dependent manner. As cited in Arjun et al., 2012, Species like Chlorella minutissima are identified in the wastewater oxidation ponds in India, which will be a good candidate for setting up wastewater HRAPs. In general the productivity on a dry weight basis ranges from 23-700 $\mathrm{mg} / \mathrm{L} / \mathrm{d}$ depending upon the algal species and type of cultivation system used. Table 1: shows the list of various algal species growing at various habitats with their lipid content and lipid productivity.

Microalgae offer one of the few innovative technologies for the capture and utilization of atmospheric carbon dioxide. These microalgae can be grown in large open ponds or in closed tubular bioreactors, into which flue gases emitted from power plants can be sparged. After harvesting, the biomass can be processed downstream to obtain valuable products such as biodiesel, green manure, pigments etc. Though, the requirement for large areas of land, favorable weather conditions, enormous quantity of water, for algal cultivation can restrict the potential of microalgae based mitigation technologies, however, if the cost of production is curtailed and brought to the level of solar energy (10\% conversion), microalgae technology could become a cost-effective option for global warming mitigation. 
Table 1: Representation of algal species for growing in wastewater (Arjun et al., 2012)

\begin{tabular}{|c|c|c|c|c|}
\hline $\begin{array}{l}\text { Waste water } \\
\text { type }\end{array}$ & Micro algal species & $\begin{array}{l}\text { Biomass (DW) } \\
\text { productivity } \\
\left(\text { mg L }^{-1} \text { day }^{-1}\right)\end{array}$ & $\begin{array}{l}\text { Lipid } \\
\text { content (\% } \\
\text { DW) }\end{array}$ & $\begin{array}{l}\text { Lipid } \\
\text { productivity } \\
\left(\text { mg L L }^{-1} \text { day }^{-1}\right)\end{array}$ \\
\hline \multirow{2}{*}{$\begin{array}{l}\text { Municipal } \\
\text { sewage }\end{array}$} & Scenedesmus obliquus & 26 & 31.4 & 8 \\
\hline & Botryococcus braunii & 345.6 & 17.85 & 62 \\
\hline \multirow{3}{*}{ Agricultural } & Botryococcus braunii & 700 & $\mathrm{Nd}$ & 69 \\
\hline & Chlorella $s p$ & $2.6 \mathrm{~g} \mathrm{~m}^{-2}$ day $^{-1}$ & 9 & $\begin{array}{l}230 \mathrm{mg} \mathrm{m}^{-2} \\
\text { day }^{-1}\end{array}$ \\
\hline & $\begin{array}{l}\text { Mix of Microsporawilleana, } \\
\text { Ulothrix sps, } \\
\text { Rhizocloniumhieroglyphicum }\end{array}$ & $5.5 \mathrm{~g} \mathrm{~m}^{-2}$ day $^{-1}$ & $\mathrm{Nd}$ & $\mathrm{Nd}$ \\
\hline \multirow{3}{*}{ Industrial } & Botryococcus braunii & 34 & 13.2 & 4.5 \\
\hline & Chlorella saccharophila & 23 & 18.10 & 4.2 \\
\hline & Pleurochrysiscarterae & 33 & 12 & 4 \\
\hline
\end{tabular}

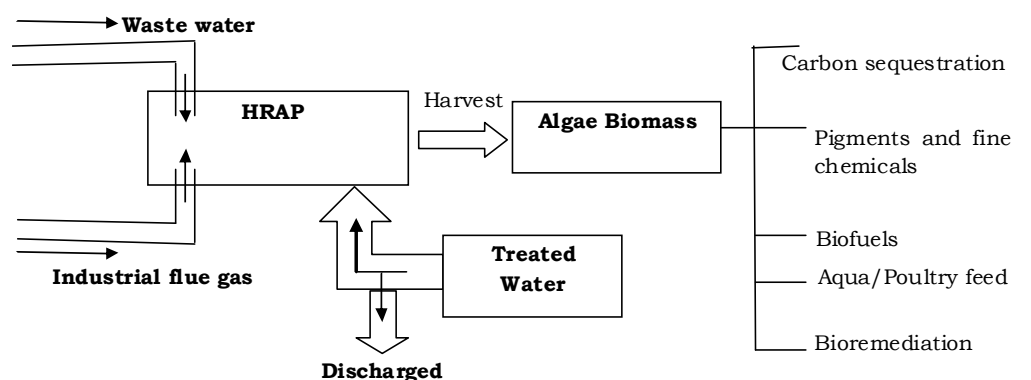

Figure. 1- A conceptual process for producing microalgal biomass through High Rate Algal Pond (HRAP) for treatment of water

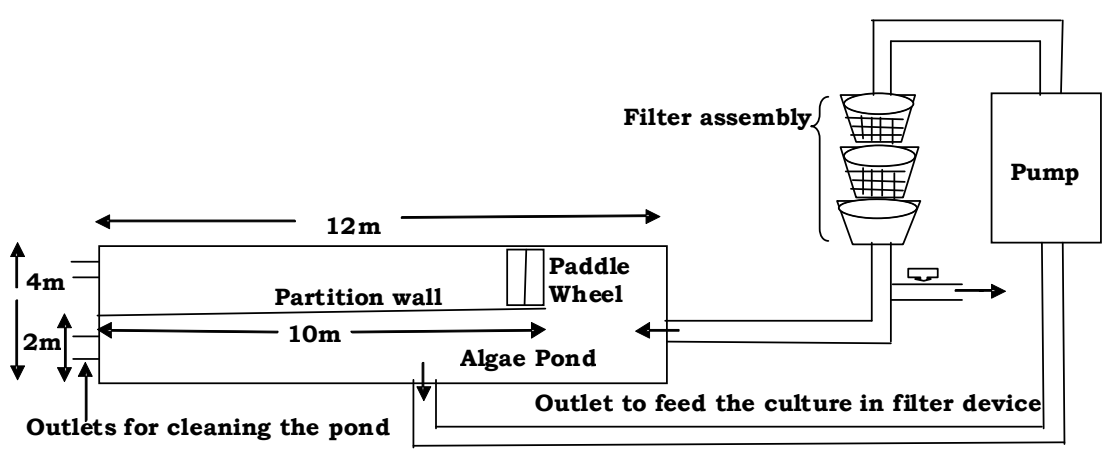

Figure. 2- Schematic diagram of a Raceway pond

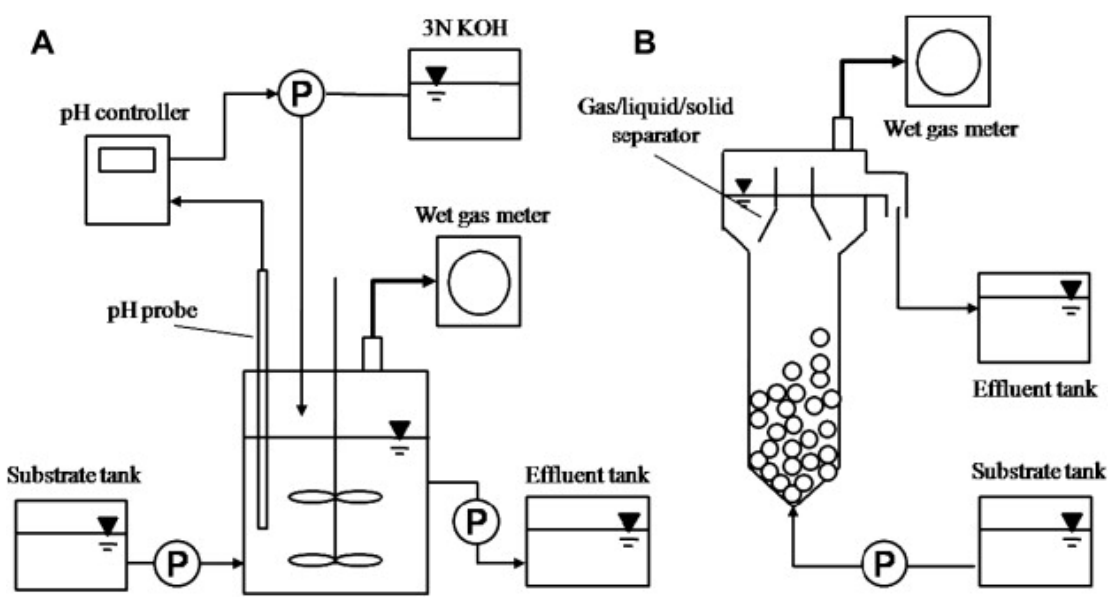

Figure. 3- CSTR for algae production for biogas using wastewater and groundwater 


\section{Conclusions:}

Carbon sequestration through microalgae has required potential for global warming mitigation. The biomass production of algae can facilitate a dual benefit situation where atmospheric carbon dioxide sequestration and value added products such as biofuels can be obtained by down-stream processing of the biomass. Though, currently projected costs of algal biomass production appear to be on higher side, however, the overall cost of production can be reduced by utilizing the waste resources and industrial emissions such as flue gases, hence a strategic significance to an environmentally sustainable society.

\section{Acknowledgement:}

Authors are thankful to Dr.W.S.Lakra, Director, ICAR-CIFE, Mumbai and Prof. T.B. Wanninayake (Chairman), Mr. F.M. Henricus (DG), and Dr. M.F.M. Fairoz (AH of FMS faculty) at Ocean University, Sri Lanka for providing the support in various forms. Financial support to W.A.A.D.L.W from Indian Council for Cultural Relations (ICCR) is also highly acknowledged.

\section{References:}

Arjun, R.K., Lipin, D. \& Thankamani, V. (2012): Review Article; An integrated process for Industrial effluent treatment and Biodiesel production using Microalgae. Research in Biotechnology, 3(1): Pp.47-60, ISSN: 2229-791X.

Chanakya, H.N., Mahapatra, D.M., Sarada, R., Chauhan, V.S. \& Abitha, R. (2012b): Sustainability of large-scale algal biofuel production in India. J. Indian Inst Sci 92:63-98

Chen, P.H., Tsai, D.D.W. \& Ramaraj, R. (2012): Growth condition study of algae function in ecosystem for $\mathrm{CO} 2$ bio-fixation. Journal of Photochemistry and Photobiology B: Biology 107: Pp.27-34.

Damiani, M.C., Popovich, C.A., Constenla, D. \& Leonardi, P.I. (2010): Lipid analysis in Haematococcus pluvialis to assess its potential use as biodiesel feedstock. Bioresour Technol 101: Pp.3801-3807.

IPCC (Intergovernmental Panel on Climate Change)(1996): Climate change 1995: Impacts, adaptations and mitigation of climate change:Scientific - technical analysis. Cambridge University Press.

Kareiva, P.M., Kingsolver, J.G. \& Huey, R.B. (1993): Introduction. In: Biotic Interactions and Global Change (eds Kareiva, P.M., Kingsolver, J.G. \& Huey, R.B.). Sinauer Associates Inc., Sunderland, MA, Pp. 1-6.
Mahapatra, D.M., Chanakya, H.N. \& Ramachandra, T.V., (2013a): Euglena sp. as a suitable source of lipids for potential use as biofuel and sustainable wastewater treatment. J. Appl. Phycol. 25, Pp.855-865.

Mahapatra, D.M., Chanakya, H.N. \& Ramachandra, T.v., (2013b): Treatment efficacy of algae based sewage treatment plants. Environ. Monit. Assess. 185, Pp.7145-7164.

Ramachandra, T.V., Mahapatra, D.M., Karthick, B. \& Gordon, R. (2009): Milking diatoms for sustainable energy: biochemical engineering versus gasoline-secreting diatom solar panels. Ind Eng Chem Res 48:8769-8788.

Sandeep, K.P., Shukla, S.P., Harikrishna, V., Muralidhar, A.P.,Vennila, A., Purushothaman, C.S. \& Kumar, R.R. (2013): Utilization of inland saline water for Spirulina cultivation, Journal of water reuse and desalination, Doi: 10.2166/wrd.2013.102.

Sandeep, K.P., Shukla, S.P., Vennila, A., Purushothaman, C.S. \& Manjulekshmi, N. (2015): Cultivation of Spirulina (Arthrospira) platensis in low cost seawater based medium for extraction of value added pigments, Indian Journal of Geo-marine Sciences , 44(3)(In Press).

Sawayama, S., Minowa, T. \& Yokoyama, S.Y. (1999): Possibility of renewable energy production and $\mathrm{CO}_{2}$ mitigation by thermochemical liquefaction of microalgae , Biomass \& Bioenergy, 17: Pp.33-39.

Victor, D. G., Zhou, D., Ahmed, E. H. M., Dadhich, P. K., Olivier,J.G. J., Rogner,H.H., Sheikho, K. \& Yamaguchi, M. (2014): Introductory Chapter. In: Climate Change 2014: Mitigation of Climate Change.Cambridge University Press, Cambridge, United Kingdom and New York, NY, USA.

Woertz, I., Feffer, A., Lundquist, T. \& Nelson, Y. (2009): "Algae Grown on Dairy and Municipal Wastewater for Simultaneous Nutrient Removal and Lipid Production for Biofuel Feedstock" Journal of Environmental Engineering 135.11 Pp.1115-1122. 